\title{
Shot-gun proteome and transcriptome mapping of Jujube floral organ and identification of a pollen-specific S-locus F- box gene
}

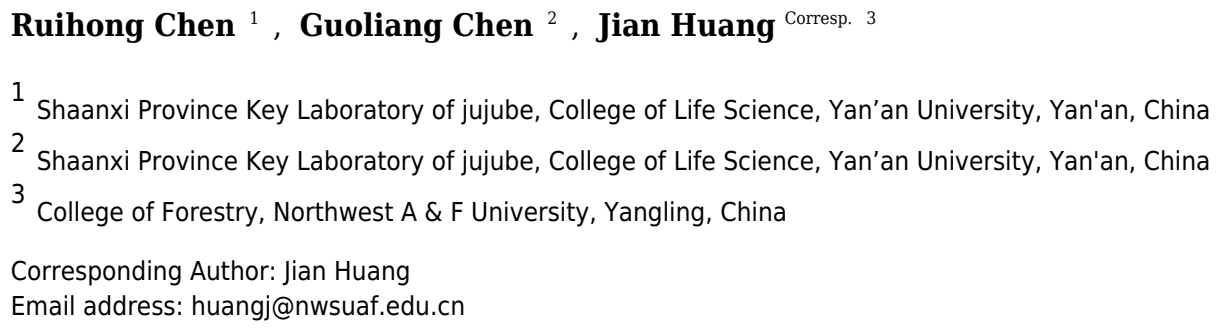

The flower is a plant reproductive organ that forms part of the fruit produced as the flowering season ends. While the number and identity of proteins expressed in a Jujube (Ziziphus jujuba Mill.) flower is currently unknown, integrative proteomic and transcriptomic analyses provide a systematic strategy of characterizing the floral biology of plants. We conducted a shotgun proteomic analysis on Jujube flowers by using a filteraided sample preparation tryptic digestion, followed by LC-MS/MS. In addition, transcriptomics analyses were performed on HiSeq2000 sequencers. In total, 7853 proteins were identified accounting for nearly $30 \%$ of the 'Junzao' gene models $(27,443)$. Genes identified in proteome generally showed higher RPKM (Reads Per Kilobase per Million mapped reads) values than undetected genes. Gene ontology categories showed that ribosomes and intracellular organelles were the most dominant classes and accounted for $17.0 \%$ and $14.0 \%$ of the proteome mass, respectively. The top-ranking proteins with iBAQ $>10^{10}$ included non-specific lipid transfer proteins, histones, actin-related proteins, fructose-bisphosphate aldolase, Bet v I type allergens, etc. In addition, we identified one pollen-specificity S-locus F-box-like gene located on the same chromosome as the S-RNase gene. Both of these may activate the behaviour of gametophyte self-incompatibility in Jujube. These results reflected the protein profile features of Jujube flowers and contributes new information important to the Jujube breeding system. 


\section{Shot-gun proteome and transcriptome mapping of Jujube}

2 floral organ and identification of a pollen-specific S-locus F-

\section{3 box gene}

4

5 Ruihong Chen ${ }^{1}$ Guoliang Chen ${ }^{1}$ Jian Huang ${ }^{1,2}$

7 Ruihong Chen: chenruihong328 @163.com;

8 Guoliang Chen: glc9359@163.com

9 Jian Huang: huangj@nwsuaf.edu.cn

10 Correspondence: huangj@nwsuaf.edu.cn

11

$12{ }^{1}$ Shaanxi Province Key Laboratory of jujube, College of Life Science, Yan'an University,

13 Yan'an,716000, China

$14{ }^{2}$ College of Forestry, Northwest A \& F University, Yangling, 712100, China

15

16

17

18

19

20

21

22 


\section{Abstract}

24 The flower is a plant reproductive organ that forms part of the fruit produced as the flowering 25 season ends. While the number and identity of proteins expressed in a Jujube (Ziziphus jujuba 26 Mill.) flower is currently unknown, integrative proteomic and transcriptomic analyses provide a 27 systematic strategy of characterizing the floral biology of plants. We conducted a shotgun 28 proteomic analysis on Jujube flowers by using a filter-aided sample preparation tryptic digestion, 29 followed by LC-MS/MS. In addition, transcriptomics analyses were performed on HiSeq2000 30 sequencers. In total, 7853 proteins were identified accounting for nearly $30 \%$ of the 'Junzao' gene 31 models $(27,443)$. Genes identified in proteome generally showed higher RPKM (Reads Per

32 Kilobase per Million mapped reads) values than undetected genes. Gene ontology categories 33 showed that ribosomes and intracellular organelles were the most dominant classes and accounted 34 for $17.0 \%$ and $14.0 \%$ of the proteome mass, respectively. The top-ranking proteins with iBAQ > $3510^{10}$ included non-specific lipid transfer proteins, histones, actin-related proteins, fructose36 bisphosphate aldolase, Bet v I type allergens, etc. In addition, we identified one pollen-specificity 37 S-locus F-box-like gene located on the same chromosome as the S-RNase gene. Both of these may 38 activate the behaviour of gametophyte self-incompatibility in Jujube. These results reflected the 39 protein profile features of Jujube flowers and contributes new information important to the Jujube 40 breeding system.

\section{Abbreviations}

43 LC-MS/MS - Liquid Chromatography-tandem Mass Spectrometry

44 MS - Mass Spectrometry

45 RPKM - Reads Per Kilobase per Million mapped reads

46 FDR - False discovery rate

47 CBB - Coomassie Brilliant Blue 
48 SDS-PAGE - Sodium Dodecyl Sulphate Polyacrylamide Gel Electrophoresis

49 MW - Molecular Weight

$50 \mathrm{GO}-$ Gene Ontology

51 qRT-PCR - Quantitative real-time reverse transcription-PCR

52 iBAQ - Intensity Based Absolute Quantification

53

54

55

56

57

62

Chinese Jujube (Ziziphus jujuba Mill.) is one of the most popular fruit trees in China. The fruits are valued for their good taste, high nutritional and medical value (Liu et al. 2014; Huang et al. 2016). Increasing economic value of Chinese Jujube has resulted in an increase in cultivation acreage.

Flowers are a critical reproductive organ and are the origin of the valuable fruits. They begin to develop in early June, originating from the leaf axil with shoot growth, and continue to be produced until the end of October in northern China (Niu et al. 2015). Jujube flowers also produce abundant nectar, and honey made from Jujube nectar is one of the most popular types of honey in China. However, Jujube flowers are small and drop easily; $87.9-99.9 \%$ of the flowers and $68.5 \%$ of young fruits usually drop during development, and only $1.1 \%$ of the fruits reach maturity on average (Liu et al. 2009). Therefore, understanding Jujube floral biology is important and may provide insights into fruit setting and Jujube breeding. Although several studies have focused on the biology of flower differentiation (He et al. 2009; Song et al. 2013; Niu et al. 2011), a global analysis of protein expression in Jujube flowers is needed to understand floral biology. 
74 Proteomics provide a comprehensive and quantitative approach to identify proteins that are

75

76

77

78

79

80

81

82

83

84

85

86

87

88

89

90

91

92

93

94

95

96

97

98

99

expressed in a given organ, tissue, or cell line. With the advance in high-resolution mass spectrometry (MS) - based shotgun proteomics (Mann et al. 2013), several complete proteome maps have been assembled in recent years. However, these studies were restricted to model organisms (Wilhelm et al. 2014; Kim et al. 2014; Baerenfaller et al. 2008). Recently, wholegenome sequencing has been applied to more organisms, and the developed gene models have provided information on the theoretical protein-coding capacity of an organism. These advances have enabled complete proteome analysis for more species. Since the first proteome map of a model plant species, Arabidopsis thaliana, was assembled (Baerenfaller et al. 2008), rapid progress in plant proteome has been made in various plant species at different tissue levels, such as fruit, seeds, flowers and leaves roots (Zeng et al. 2011; Girolamo et al. 2012; Dai et al. 2013; Zhu et al 2015). Undoubtedly, sequencing of the Jujube genome will also contribute to the proteomics study of jujube (Liu et al. 2014).

Some genes specifically expressed in floral organs have been shown to contribute to flower development and reproductive function. In a previous study, gametophyte self-incompatibility (GSI) induced in Z. jujuba led to high percentage of seedless fruits (Asatryan and Tel-Zur 2013). Self-incompatibility/compatibility is controlled by the pistil S determinant ribonuclease (S-RNase) and the pollen S determinant F-box (SFB) gene(s). The GSI has been well characterized in some core-eudicots, such as Solanaceae, Plantaginaceae and Rosaceae. We have previously identified an S-RNase candidate gene in the chromosome 1 of the assembled 'Junzao' Jujube genome (Huang et al. 2016). However, the SFB candidate genes specifically expressed in pollens have not been identified.

8 A combination of transcriptome and proteome technologies offers a new comprehensive approach

99 to identify the genes involved in developmental systems and environmental responses. This study 
100 is the first to generate a draft proteome map of Jujube flowers based on the liquid chromatography-

101 tandem mass spectrometry (LC-MS/MS). To further improve the molecular knowledge of GSI in

102 Z. jujuba, we attempt to identify the SFB gene(s) specially expressed in anthers/pollens linked to

103 the S-RNase gene. Information from our study will provide a better understanding of Jujube flower

104 development and the breeding system.

105

106 Materials and methods

\section{Sample collection}

108 Budding flowers were collected from nine year old Jujube trees (Ziziphus jujuba 'Junzao') in 2013.

109 We collected two biological replicates of flower samples from each of two trees. The collected

110 flowers were immediately immersed in liquid nitrogen, and stored at $-80^{\circ} \mathrm{C}$ for transcriptome and

111 proteome analysis.

112

\section{Protein extraction and quality determination}

115 We selected one sample replicate for proteome analysis. The trichloroacetic acid (TCA)/acetone

116 precipitation method was used to extract protein from Jujube flowers (Wu et al. 2014). Briefly,

117 frozen flowers were ground in liquid nitrogen and precipitated with TCA/acetone (1:9) overnight

118 at $-20{ }^{\circ} \mathrm{C}$. Then the homogenate was centrifuged $(7000 \times \mathrm{g}, 30 \mathrm{~min})$ and washed three times with

119 acetone. The precipitated proteins were freeze-dried and then re-suspended in $800 \mu$ of SDT buffer

120 (4\% SDS, $100 \mathrm{mM}$ DTT, $150 \mathrm{mM}$ Tris-HCl, $\mathrm{pH}$ 8.0). After $15 \mathrm{~min}$ of incubation in boiling water,

121 the homogenate was fractionated by ultrasound $(80 \mathrm{~W}, 10 \mathrm{~s}, 10$ times) on ice. The homogenate

122 was centrifuged at $14000 \times \mathrm{g}$ at $4{ }^{\circ} \mathrm{C}$ for $30 \mathrm{~min}$, and the supernatant was collected. Finally, the

123 protein concentration was determined using a bicinchoninic acid protein assay kit (BCA,

124 Beyotime, China) and adjusted to $5 \mu \mathrm{g} / \mu \mathrm{l}$. Protein was also analysed by electrophoresis on a $12.5 \%$ 
125 sodium dodecyl sulphate polyacrylamide gel electrophoresis (SDS-PAGE) gel $(7 \mathrm{~cm} \times 20 \mathrm{~cm})$ and

126 stained with Coomassie Brilliant Blue (CBB) staining buffer (Gelcode blue, Pierce, USA).

127

128

In-solution protein digestion

129

130 Proteins were digested by following the filter-aided sample preparation (FASP) procedure

131 (Wisniewski et al. 2009). Total-protein samples $(50 \mu \mathrm{g})$ were incorporated into $30 \mu \mathrm{l}$ of SDT buffer

132 (4\% SDS, $100 \mathrm{mM}$ DTT, $150 \mathrm{mM}$ Tris-HCl, $\mathrm{pH} 8.0)$ and then heated at $95^{\circ} \mathrm{C}$ for $5 \mathrm{~min}$. Thereafter,

$133200 \mu \mathrm{l}$ of UA buffer ( $8 \mathrm{M}$ urea, $150 \mathrm{mM}$ Tris-HCl pH 8.0) was added to the protein solution, mixed

134 to remove the detergent, DTT, and passed through an ultrafiltration unit with a nominal molecular

135 weight (MW) cut-off of $30 \mathrm{kDa}$ (Cat No. MRCF0R030, Millipore) to remove other low-molecular-

136 weight components. Then, $100 \mu$ of $0.05 \mathrm{M}$ iodoacetamide in UA buffer was added, and the

137 samples were incubated for $20 \mathrm{~min}$ in the dark. The filter was washed three times with $100 \mu \mathrm{l}$ of

138 UA buffer, followed by two washes with $100 \mu \mathrm{l}$ of $25 \mathrm{mM} \mathrm{NH} \mathrm{HCO}_{3}$. Finally, $2 \mu \mathrm{g}$ of trypsin

139 (Promega) was added, the protein suspension was digested overnight at $37{ }^{\circ} \mathrm{C}$ and the resulting

140 peptides were collected as the filtrate.

\section{Peptide Fractionation with Strong Cation Exchange (SCX) Chromatography}

142 Peptides were fractionated by SCX chromatography using an AKTA Purifier system (GE

143 Healthcare). The dried peptide mixture was reconstituted and acidified with $2 \mathrm{ml}$ of buffer A (10

$144 \mathrm{mM} \mathrm{KH}_{2} \mathrm{PO}_{4}$ in $25 \%$ of acetonitrile $\left.(\mathrm{ACN}), \mathrm{pH} 2.7\right)$ and loaded onto a Poly SULFOETHYL $4.6 \times$

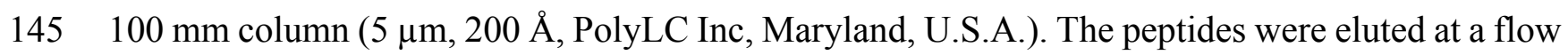

146 rate of $1 \mathrm{ml} / \mathrm{min}$ using a gradient of $0-10 \%$ buffer $\mathrm{B}\left(500 \mathrm{mM} \mathrm{KCl}, 10 \mathrm{mM} \mathrm{KH}_{2} \mathrm{PO}_{4}\right.$ in $25 \%$ of

$147 \mathrm{ACN}, \mathrm{pH} 2.7$ ) for $2 \mathrm{~min}, 10-20 \%$ buffer B for $25 \mathrm{~min}, 20-45 \%$ buffer B for 5 min, and 50\% -

$148100 \%$ buffer B for $5 \mathrm{~min}$. The eluents were monitored by absorbance at $214 \mathrm{~nm}$ and fractions were

149 collected every $1 \mathrm{~min}$. The collected fractions (approximately 30) were combined into 25 pools

150 and desalted on C18 Cartridges (Empore ${ }^{\mathrm{TM}}$ SPE Cartridges C18 (standard density), bed I.D. 7 mm, 
151 volume $3 \mathrm{ml}$, Sigma). Each fraction was concentrated by vacuum centrifugation and reconstituted

152 in $40 \mu \mathrm{l}$ of $0.1 \%(\mathrm{v} / \mathrm{v})$ trifluoroacetic acid. All samples were stored at $-80{ }^{\circ} \mathrm{C}$ until LC-MS/MS

153 analysis could be conducted.

\section{Liquid Chromatography (LC) - Electrospray Ionization (ESI) Tandem MS (MS/MS)}

\section{Analysis by Q Exactive.}

156 Experiments were performed on a Q Exactive mass spectrometer that was coupled to a nanoflow

157 HPLC (Easy nLC, Proxeon Biosystems, now Thermo Fisher Scientific). Each fraction (6 4 l) was

158 injected for Nano LC-MS/MS analysis. The peptide mixture $(5 \mu \mathrm{g})$ was loaded onto a C18-

159 reversed phase column (Thermo Scientific Easy Column, $10 \mathrm{~cm}$ long, $75 \mu \mathrm{m}$ inner diameter, $3 \mu \mathrm{m}$

160 resin) in buffer A (0.1\% formic acid) and separated using a linear gradient of buffer B (80\%

161 acetonitrile and $0.1 \%$ formic acid) at a flow rate of $250 \mathrm{nl} / \mathrm{min}$ controlled by IntelliFlow technology

162 over $60 \mathrm{~min}$.

163

164 MS data were acquired dynamically using a data-dependent top10 method by choosing the most 165 abundant precursor ions from the survey scan $(300-1800 \mathrm{~m} / \mathrm{z})$ for HCD fragmentation. Target 166 value determination was based on predictive automatic gain control (pAGC). The dynamic 167 exclusion duration was $60 \mathrm{~s}$. Survey scans were acquired at a resolution of 70000 at $200 \mathrm{~m} / \mathrm{z}$, and 168 for HCD spectra, the resolution was set to 17500 at $200 \mathrm{~m} / \mathrm{z}$. The normalized collision energy was

$16930 \mathrm{eV}$, and the underfill ratio, which specifies the minimum percentage of the target value likely 170 to be reached at maximum fill time, was defined as $0.1 \%$. The instrument was run in peptide 171 recognition mode. 
173 RNA extraction and Transcriptome analyses

174 Total RNA of whole budding flowers was isolated using an RNA prep Pure Tissue Kit (Tiangen,

175 Beijing) for RNA extraction and then treated with RNase-free DNase I treatment (Promega, USA).

176 RNA purity was checked using the NanoPhotometer ${ }^{\circledR}$ spectrophotometer (IMPLEN, CA, USA).

177 RNA concentration was measured using Qubit 2.0 Flurometer (Life Technologies, CA, USA).

178 RNA integrity was assessed using an RNA Nano 6000 Assay Kit of the Bioanalyzer 2100 system

179 (Agilent Technologies, CA, USA). Finally, RNA degradation and contamination was visualized

180 on $1 \%$ agarose gels. A total of $3 \mu \mathrm{g}$ of RNA per sample was used as input material for the RNA

181 sample preparations. Sequencing libraries were generated using NEBNext ${ }^{\circledR}$ Ultra ${ }^{\mathrm{TM}}$ RNA Library

182 Prep Kit for Illumina ${ }^{\circledR}(\mathrm{NEB}, \mathrm{USA})$ according to manufacturer's recommendation. The libraries

183 were sequenced on an Illumina HiSeq 2000 platform and 100 bp paired-end reads were

184 generated. The raw-sequence reads data are deposited in NCBI Sequence Read Archive

185 (SRX1518648 and SRX1518646).

186

187 After quality control of raw reads, filtered reads were mapped to the 'Junzao' genome using

188 Tophat2 (Kim et al. 2013). Total aligned read numbers were normalized by gene length and 189 sequencing depth for an accurate estimate of expression levels (Robinson et al. 2010). HTSeq 0.6.1

190 was used to count the reads mapping to each gene (Anders et al. 2014). In addition, the RPKM

191 (Reads Per Kilobase per Million mapped reads) of each gene was calculated based on the length

192 of the gene to represent the expression level (Mortazavi et al. 2008).

193

194 Sequence Database Searching and Data Analysis

195

196 The mass spectrometric raw data from the top10 method were analysed using MaxQuant 1.3.0.5

197 (Cox and Mann 2008). MS/MS data were searched against the gene predicted gene models of 198 Ziziphus jujuba 'Junzao' (Accession: LPXJ00000000 and Dryad Digital Repository. 
doi:10.5061/dryad.83fr7). An initial search was set at a precursor mass window of $6 \mathrm{ppm}$. The search followed an enzymatic cleavage rule of Trypsin/P and allowed a maximum of two missed cleavage sites and a mass tolerance of $20 \mathrm{ppm}$ for fragment ions. Enzyme = Trypsin, Missed cleavage $=2$, Fixed modification: Carbamidomethyl $(\mathrm{C})$, Variable modification: Oxidation $(\mathrm{M})$, Decoy database pattern $=$ decoy. The cut-off of global false discovery rate $($ FDR) for peptide and protein identification was set to 0.01 . The iBAQ algorithm was used to calculate the approximate abundance of each protein, which normalizes the summed peptide intensities by the number of theoretically observable peptides of the protein (Schwanhausse et al. 2011).

\section{Gene Ontology (GO) term enrichment analysis of expressed genes and proteins}

GO term enrichment analysis was conducted for expressed genes and proteins in the Jujube flower 209 using the $\mathrm{R}$ package TopGO, and is available from Dryad Digital Repository (doi:10.5061/dryad.83fr7). GO term enriched results for the transcriptome and proteome were compared for the three aspects of cell components, molecular function and biological progress.

\section{Gene expression validation by quantitative Real-time PCR (qRT-PCR) Analysis}

213 We performed a qRT-PCR analysis to validate the relative gene expression levels in the flowers.

214 RNA samples from the same flower samples used for RNA-sequencing analysis were extracted

215 using the same method as described above. cDNA was synthesized using a PrimeScript ${ }^{\mathrm{TM}} \mathrm{RT}^{\mathrm{T}}$ 216 reagent kit with gDNA Eraser (TaKaRa, Dalian, China) according to the manufacturer's 217 instruction. We selected 30 genes with different levels of RPKM and iBAQ values for qRT-PCR 218 analyses (Table S1). The primers were designed using Primer-BLAST online software 219 (http://www.ncbi.nlm.nih.gov/tools/primer-blast/). Primer specificities were initially verified by

220 PCR amplification of a single product and product size was visualized after electrophoresis on a 221 1.2\% agarose gel. The cDNAs were then amplified in a Bio-Rad CFX Real-Time System (Bio222 Rad, Hercules, CA, USA) with SYBR Premix Ex Taq TM II (Takara, Dalian, China). The qRT223 PCR amplification protocol was set at $95^{\circ} \mathrm{C}$ for $3 \mathrm{~min}, 95^{\circ} \mathrm{C}$ for $10 \mathrm{~s}, 40$ cycles of $95^{\circ} \mathrm{C}$ for $10 \mathrm{~s}$ 
224 and $58^{\circ} \mathrm{C}$ for $10 \mathrm{~s}$, and finally, $72^{\circ} \mathrm{C}$ for $30 \mathrm{~s}$. Three replicates were performed for each gene. The

225 UBQ gene (Zj.jz021445712) of Jujube was chosen as an internal reference gene for normalization

226 (Zhang et al. 2015). The average threshold cycle (Ct) was normalized, and the relative expression

227 was calculated using the $2^{-\Delta \mathrm{Ct}}$ method.

228 Identification of S-locus F-box （SFB） genes

229 We used previously reported S-locus F-box genes as queries to BLAST search 'Junzao' gene

230 models, such as those from Plantaginaceae (6 S-locus F-box (SLF) genes), Solanaceae (35 SLFs),

231 and Maleae (22 S-locus F-box brothers (SFBB)), 8 SLF-like genes and 3 SFB genes of Prunus.

232 Because we have identified the S-RNase gene (Zj.jz035833030) located on the linkage group (LG)

2331 of the assembled 'Junzao' genome, we treated the newly identified F-box genes located on LG1

234 as potential SFB genes and then subjected them to phylogenetic analysis with the known reported

235 S-locus F-box genes. All the amino acid sequences were aligned and a neighbour-joining tree was

236 constructed using Mega 6.0.6 (Tamura et al. 2013). Then, RPKM values of those F-box genes

237 were calculated based on the transcriptomic analysis of leaves, flowers, shoot and fruits based on

238 the previous report (Huang et al. 2016). We further performed tissue-specific expression analysis

239 of those F-box genes among different tissues/organs (leaves, shoot, young fruit, ripe fruit, pollen,

240 pistil, petal, flower disc) using RT-PCR. RNA extraction, cDNA synthesis and primer design

241 (Table S3) were performed as described above. PCR was performed in using $2 \times$ GoldStar Best

242 MasterMix (CWBIO, Beijing) according to its protocol. PCR products were visualized on a $1.2 \%$

243 agarose gel after electrophoresis. 


\section{Results}

245 Transcriptome and Proteome analysis of Jujube flowers

246 RNA sequencing of two independent flower samples (flower 1 and 2) on an Illumina Hiseq 2000

247 platform generated 52.8 and 59.4 million clean paired-end reads after quality control for flower 1

248 and 2, respectively (Table S1). In general, $90.1 \%$ of the reads from flower 1 and $92.2 \%$ of flower

2492 were mapped onto the 'Junzao' Jujube gene models, and $88.1 \%$ and $90.3 \%$ of reads were mapped 250 to unique sites, respectively. A total of $18646(67.9 \%)$ and $17995(65.6 \%)$ genes had RPKM 251 values $\geq 1$ in two samples, respectively (Table S2). The two samples showed a strong correlation 252 (Pearson $r=0.96, P<0.01$ ) on the RPKM metrics. In addition, the rank pattern of expression 253 levels of the selected 30 genes generated by qRT-PCR analysis showed a linear correlation with 254 their RPKM values $(r=0.95, P<0.01)$. Taken together, both correlation analyses and independent 255 qRT-PCR evaluation confirmed the reproducibility and validity of the relative expression levels 256 based on the RPKM methods in the transcriptome analysis (Table S2).

257

258 In total, $80802 \mathrm{MS} / \mathrm{MS}$ spectra were obtained and evaluated against the 'Junzao' Jujube gene 259 prediction database. We identified 7853 proteins with 42925 unique peptides originating from 26080394 tandem mass spectrometry spectrum assignments with a false-discovery rate (FDR) below $2611 \%$, which accounts for nearly 30\% of all predicted 'Junzao' gene models (27 443).

\section{Comparison of the proteome and transcriptome}

263 We compared the transcriptome and proteome data generated from the flower samples based on 264 the 'Junzao' gene models. As shown in the Venn diagram (Fig. 1), 94\% of genes identified by MS

265 as protein could also be detected at the mRNA expression level (RPKM $\geq 1$ ), and only 80 genes 266 were missing. The identified proteins accounted for $41.2 \%$ of the transcripts with RPKM values $\geq$ 2671. 
269 The RPKM values of all detected genes show a bimodal distribution (Fig. 2A) in which 81.27\% 270 (17 995) and 64.08\% $(14,182)$ of genes had signals of RPKM values $\geq 1$ and 5 , respectively. When

271 the criterion was set at 5, the left shoulder of the bimodal distribution line disappeared and 272 transformed into a Gaussian distribution. By comparison, the identified protein abundance showed 273 a broader distribution range than the filtered mRNA abundance (Fig. 2A, B). Among the 7497 274 genes identified in the proteomic analysis, only $129(1.6 \%)$ and $473(6.0 \%)$ of genes had RPKM 275 values $<1$ and 5, respectively. RPKM values of the genes identified in the proteome or those not 276 identified differ clearly (Fig. 2C). We also found that the RPKM-based transcript abundance values 277 correlated (Spearman's correlation 0.5) well with iBAQ-based protein abundance values in Jujube 278 flowers (Fig. 2D). The top10 categories of $\mathrm{GO}$ for the proteome and the corresponding 279 transcriptome in the three aspects of cell components, biological progress and molecular functions 280 are shown in figure 3 . The ranking patterns were generally similar in the transcriptome and 281 proteome in the three aspects, and the highest-ranking categories were consistent among the three 282 aspects.

\section{Protein abundance}

284 The iBAQ values are considered as estimates of the absolute amount of each protein. The most 285 abundant 224 proteins $(2.85 \%)$ constituted $50 \%$ of the Jujube flower proteome, and the 691 most 286 abundant proteins, representing 80\% abundance, dominated the total protein abundance (Fig.4). 287 The 41 most abundant proteins comprised $20 \%$ of the proteome. The top 7 proteins with iBAQ 288 values $>10^{10}$ included two non-specific lipid transfer proteins, histones, actin-related proteins, 289 fructose-bisphosphate aldolase, Bet v I type allergens and unknown proteins. However, ribosomal 290 proteins with six members showed the most abundant protein mass (50381000 000) within the 291 top20 proteins (Supplementary Data). 
293 Abundance values of each protein reflect their contribution to the total proteome (Nagaraj et al.

294 2011). As shown in the GO category, more members of those proteins did not necessarily possess

295 a higher proportion of the protein mass (Fig S1. A). Some protein classes contributed a

296 significantly higher proportion of the total protein mass compared with the corresponding

297 identified protein number. Based on the cellular components, we identified 175 (2.3\%) different

298 ribosomes accounting for $17 \%$ of the total protein mass in our data (FigS1. A). Similarly, the

299 intracellular components with 230 genes $(3.1 \%)$ contributed $13.96 \%$ of the proteome mass. This

300 large difference was also observed in the "structural constituents of ribosomes" belonging to

301 'molecular function' and 'translation' belonging to 'biological progress' (Fig S1. B, C). In contrast,

302 integral membrane proteins accounted for $2.3 \%$ of the protein mass but contributed much less to

303 the proteome $(1.0 \%$ of total protein mass $)$.

304 Identification of SFB gene

305 We first identified seven candidate SFB genes (Table S3) in LG1 around S-RNase

306 (Zj.jz035833030) by Blastp analysis. Phylogenetic analysis showed that S-locus F-box genes

307 belonging to Plantaginaceae, Solanaceae, and Maleae clustered into one group. Jujube SFB genes

308 were located between Prunus SFB genes and SLFL genes (Fig. 5). According to the transcriptomic

309 analysis, we found that No. 5 (Zj.jz026591005) and No. 7 (Zj.jz039541036) were slightly

310 expressed in budding flowers while the other four genes were expressed in several tissues (Fig.

311 6A). RT-PCR analyses showed that Zj.jz039541036 was strongly expressed in pollens while

312 Zj.jz026591005 was only weakly detected in all flower organs. In contrast to RT-PCR results,

313 Zj.jz027555002 was not detected in any of the tissues (Fig. 6B). Therefore, we consider

314 Zj.jz039541036 as the candidate SFB gene of Z. jujuba.

\section{Discussion}

316 In this study, we used an FASP-SCX-LC-MS/MS method to resolve the proteome of Jujube flower 
317 organs. In total, we identified 7497 proteins that accounted for nearly $30.0 \%$ of all predicted

318 'Junzao' gene models (27 443). This depth was similar to the results of the shotgun proteome study

319 of Arabidopsis flowers (Baerenfaller et al. 2008), in which 7040 proteins (26.1\% of all gene

320 models) were identified and represented nearly 50\% of all identified Arabidopsis genes in the

321 proteome map. Compared to the improved LC-MS/MS technologies, two-dimensional

322 electrophoresis/mass spectrometry (2-DGE/MS) and multi-dimensional protein identification

323 technology (MudPIT) approaches only identified 2400 floral proteins in wild Arabidopsis flowers

324 (Feng et al. 2009). Lack of genome resources could undermine the efficiency of protein

325 identification. In one study, only 1488 proteins were obtained from the fruit of Punica granatum

326 by nanoliquid chromatography high-resolution tandem mass spectrometry (Capriotti et al. 2013),

327 and 554 of the 2043 peptides could not be annotated in the proteome of the midgut of Spodoptera

328 litura larvae by shotgun ESI-MS (Liu et al. 2010). In the present study, 58\% of the genes with

329 RPKM values $\geq 1$ were still not covered by the proteome in Jujube flowers, suggesting the

330 limitation of the present research strategies. The flower is a complex plant organ that secretes many

331 sugars that likely interfere with protein separation (Righetti and Boschetti 2016). When the flower

332 is separated into different organs, such as pistil, petal, stigma, and style, the depth of the flower

333 proteome may be further increased. In general, plant proteomics often identify fewer proteins than

334 animal and human cell or organ proteomics because of higher amount of proteins in animals

335 compared to the protein levels in plant biomass (for example, cell walls contain 90-95\%

336 polysaccharides and 5-10\% proteins). Therefore, a new strategy for protein extraction should be

337 considered (e.g., CPLL; Righetti and Boschetti 2016).

338

339 Recent advances in genome sequencing and proteomics make it possible to study protein

340 abundance and its relationship to corresponding mRNA levels. The distribution pattern of all

341 transcripts in transcriptome showed a bimodal distribution. Transcripts in the left part of bimodal

342 distributions (Fig. 2a) possessed less than one copy and were not expressed as functional protein 
343 in tissues (Hebenstreit et al. 2011). When the RPKM value criterion increased to 5, the RPKM

344 values of transcripts showed a Gaussian distribution and were close to the distribution of genes

345 detected in the proteome (Fig. 2a). In addition, the expression levels of those genes that have their

346 corresponding proteins identified in the proteome were generally higher than those of which the

347 proteins were not detected in the proteome (Fig. 2b). Genome-scale proteome analysis of $A$.

348 thaliana preferentially detected proteins that are expressed at higher transcript frequencies

349 (Baerenfaller et al. 2008). Feng et al. (2009) also found that proteins encoded by genes with

350 relatively high levels of expression were detected with greater frequency in the proteome of wild

351 Arabidopsis flower investigated by 2-DGE/MS and MudPIT approaches. These results confirm

352 that genes with higher expression levels have a high likelihood of being translated into active 353 protein.

355 Unlike the observed domination of RuBisCO (ribulose-1,5-bisphosphate carboxylase/oxygenase) 356 in leaf proteins $(>50 \%)$ and of storage proteins in seeds $(>80 \%)$, in the Jujube flower proteome, 357 ribosomal proteins were the most abundant protein class, accounting for $17 \%$ of the total protein 358 mass. This reflects the different biological functions of floral organs in the role of protein 359 composition. Other abundant proteins also contribute to the special features of flowers. Non360 specific lipid transfer proteins are abundant and widely distributed in plants, representing as much 361 as 4\% of total soluble proteins (Liu et al. 2015). Plant actin-related protein are also an important

362 component and are widely distributed in plant cells. Fructose-bisphosphate aldolase is a key 363 enzyme involved in glycolysis, gluconeogenesis in the cytoplasm, and in the Calvin cycle.

364 Members of fructose-bisphosphate aldolase that are highly expressed in flowers may play an 365 important role in pollen tube growth (Lu et al. 2012; Tang. 2013). In addition, abundant Bet v I 366 type allergens make Jujube flowers an allergen source for humans. This finding could also 367 characterize the feature of Jujube flower based on proteomics. 
369 GSI is an important feature of reproductive biology in core-eudicots and exhibited in Z. jujuba. It

370 has been well characterized that GSI is controlled by one pistil-specificity S-RNase and a single

371 (or multiple) pollen-specificity F-box gene(s). We found there were some differences between the

372 RNA-Seq and RT-PCR. According to the transcriptomic analysis, we were failed to identify a

373 flower-specificity F-box gene linked to S-RNase based on the transcriptomic analysis (Fig. 6A).

374 In contrast, we found a single pollen-specific F-box gene (Zj.jz 039541036) based on RT-PCR

375 analysis after dissecting the flower into its component organs. Most likely this is because the RNA-

376 Seq of whole flowers is not reflecting the gene expression level in specific organs or tissues.

377 Phylogenetic analysis revealed that the Jujube SFB gene was close to that of Prunus (Fig. 5), in

378 which GSI exhibited a distinct system of recognition between pollen and pistil involving a single

379 SFB gene. This contrasts with multiple F-box genes that are activated in other plants (Matsumoto 380 and Tao 2016). With the formerly identified S-RNase gene in Z. jujuba, therefore, we concluded

381 that Jujube GSI behaviour was like Prunus and controlled by the S-RNase and a single SFB gene 382 together. This finding will facilitate further characterization of the underlying molecular 383 mechanism of the reproductive biology of Z. jujuba.

384

385

386

\section{References}

387

388

389

390

391

392

393

394

395

396

Anders S, Pyl PT, Huber W(2014) HTSeq-A Python framework to work with high-throughput sequencing data, Bioinformatics .31:166-169

Asatryan A, Tel-Zur N. 2013. Pollen tube growth and self-incompatibility in three Ziziphus species (Rhamnaceae). Flora - Morphology, Distribution, Functional Ecology of Plants 208:390-399. Baerenfaller K, Grossmann J, Grobei MA, Hull R, Hirsch-Hoffmann M, Yalovsky S, Zimmermann P, Grossniklaus U, Gruissem W, Baginsky S (2008) Genome-Scale proteomics reveals Arabidopsis thaliana gene models and proteome dynamics.Science 320:938-941

Capriotti AL, Caruso G, Cavaliere C, Foglia P, Piovesana S, Samperi R, Laganà A (2013) Proteome investigation of the non-model plant pomegranate (Punica granatum L.), Analytical and bioanalytical chemistry 405: 9301-9309 
397

398

399

400

401

402

403

404

405

406

407

408

409

410

411

412

413

414

415

416

417

418

419

420

421

422

423

424

425

426

427

428

429

430

431

432

433

434

Cox J, Mann M (2008) MaxQuant enables high peptide identification rates, individualized p.p.b.range mass accuracies and proteome-wide protein quantification. Nature biotechnology 26: 1367-72

Dai L, Kang G, Li Y, Nie Z, Duan C, Zeng R(2013) In-depth proteome analysis of the rubber particle of Hevea brasiliensis (para rubber tree). Plant Mol Biol 82:155-168

Feng B, Li L, Zhou X, Stanley B, Ma H(2009) Analysis of the Arabidopsis floral proteome: detection of over 2000 proteins and evidence for posttranslational modifications. Journal of integrative plant biology 51:207-23

Girolamo F, D'Amato A, Righetti PG (2012) Assessment of the floral origin of honey via proteomic tools. Journal of proteomics 75:3688-3693

He R, Zhang Q, Jiang X (2009) Observation on flower-bud morph differentiation and flower structure on jujube, Journal of Tarim University 21: 11-14

Hebenstreit D, Fang M, Gu M, Charoensawan V, van Oudenaarden A, Teichmann SA (2011) RNA sequencing reveals two major classes of gene expression levels in metazoan cells. Molecular systems biology 7:497

Huang J, Zhang CM, Zhao X, ZJ Fei, Wan KK, Zhang Z, Pang XM, YinX, Bai Y, SunXQ, Gao LZ, Li RQ, Zhang JB, Li XG(2016) The Jujube genome provides insights into genome evolution and the domestication of sweetness/acidity taste in fruit trees, Plos Genetics 12(12): e1006433.

Kim D, Pertea G, Trapnell C, Pimentel H, Kelley R, Salzberg SL. (2013) TopHat2: accurate alignment of transcriptomes in the presence of insertions, deletions and gene fusions. Genome Biology 14:R36

Kim MS, Pinto SM, Getnet D, Nirujogi RS, Manda SS, Chaerkady R, Madugundu AK, Kelkar DS, Isserlin R, Jain S, Thomas JK, Muthusamy B, Leal-Rojas P, Kumar P, Sahasrabuddhe NA, Balakrishnan L, Advani J, George B, Renuse S, Selvan LD, Patil AH, Nanjappa V, Radhakrishnan A, Prasad S, Subbannayya T, Raju R, Kumar M, Sreenivasamurthy SK, Marimuthu A, Sathe GJ, Chavan S, Datta KK, Subbannayya Y, Sahu A, Yelamanchi SD, Jayaram S, Rajagopalan P, Sharma J, Murthy KR, Syed N, Goel R, Khan AA, Ahmad S, Dey G, Mudgal K, Chatterjee A, Huang TC, Zhong J, Wu X, Shaw PG, Freed D, Zahari MS, Mukherjee KK, Shankar S, Mahadevan A, Lam H, Mitchell CJ, Shankar SK, Satishchandra P, Schroeder JT, Sirdeshmukh R, Maitra A, Leach SD, Drake CG, Halushka MK, Prasad TS, Hruban RH, Kerr CL, Bader GD, Iacobuzio-Donahue CA, Gowda H, Pandey A.(2014) A draft map of the human proteome.Nature 509:575-581

Tamura K, Stecher G, Peterson D, Filipski A, Kumar S (2013) MEGA6: Molecular Evolutionary Genetics Analysis version 6.0. Molecular Biology and Evolution:30 2725-2729.

Liu F, Zhang X, Lu C, Zeng X, Li Y, Fu D, Wu G (2015) Non-specific lipid transfer proteins in plants: presenting new advances and an integrated functional analysis, Journal of experimental botany .66: 5663-5681 
435

436

437

438

439

440

441

442

443

444

445

446

447

448

449

450

451

452

453

454

455

456

457

458

459

460

461

462

463

464

465

466

467

468

469

470

471

472

473

Liu J, Zheng S, Liu L, Li L,Feng Q (2010) Protein Profiles of the Midgut of Spodoptera litura larvae at the sixth instar feeding stage by shotgun ESI-MS approach. Journal of Proteome Research 9:2117-2147

Liu MJ, Zhao J, Cai QL, Liu GC, Wang JR, Zhao ZH, Liu P, Dai L, Yan G, Wang WJ, Li XS, Chen Y, Sun YD, Liu ZG, Lin MJ, Xiao J, Chen YY, Li XF3, Wu B, Ma Y, Jian JB, Yang W, Yuan Z, Sun XC, Wei YL, Yu LL, Zhang C, Liao SG, He RJ, Guang XM, Wang Z, Zhang YY, Luo LH (2014) The complex jujube genome provides insights into fruit tree biology.Nature communications 55:315

Liu P, Liu MJ, Zhao ZH, Liu XY, Wang JR, Yan C (2009) Investigation on the characteristics of fruiting and seed development in Chinese jujube (Ziziphus jujuba Mill.). International Society for Horticultural Science (ISHS). Leuven, Belgium. pp. 209-214

Lu W, Tang X, Huo Y, Xu R, Qi S, Huang J, Zheng C, Wu CA (2012) Identification and characterization of fructose 1,6-bisphosphate aldolase genes in Arabidopsis reveal a gene family with diverse responses to abiotic stresses. Gene 503:65-74

Mann M, Kulak NA,Nagaraj N,Cox J (2013) The coming age of complete, accurate, and ubiquitous proteomes. Molecular cell 49:583-590

Matsumoto D, Tao R. 2016. Distinct Self-recognition in the Prunus S-RNase-based Gametophytic Self-incompatibility System. The Horticulture Journal 85:289-305.

Mortazavi A, Williams BA, McCue K, Schaeffer L, Wold B (2008) Mapping and quantifying mammalian transcriptomes by RNA-Seq.Nature methods 5: 621-628

Nagaraj N, Wisniewski JR, Geiger T, Cox J, Kircher M, Kelso J, Pääbo S, Mann M (2011) Deep proteome and transcriptome mapping of a human cancer cell line. Molecular systems biology $7: 548$

Niu HL, Zhang HW, Yuan B, Li XG (2015) Flower formation and endogenous hormones dynamic in Chinese jujube. Acta Horticulturae Sinica 42: 655-664

Niu YF, Peng JY, Li L (2011) Study on morphology of flower organ and anatomical characteristics of microspore different developmental period in Chinese jujube and wild jujube. Journal of plant genetic resources 12:158-162

Righetti PG, Boschetti E (2016) Global proteome analysis in plants by means of peptide libraries and applications.Journal of proteomics 143: 3-14

Robinson MD, Oshlack A (2010) A scaling normalization method for differential expression analysis of RNA-seq data. Genome biology 11:R25

Schwanhäusser B, Busse D, Li N, Dittmar G, Schuchhardt J, Wolf J, Chen W, Selbach M (2013) Corrigendum: Global quantification of mammalian gene expression control. Nature 495: 126127

Song YQ, Li WQ, Li LL, Liu H, Lu GB(2013) Observation on jujube flowers morphology and anther characteristics. Journal of Shanxi Agricultural Sciences 41:1190-1193

Tang X (2013) New functional studies of two cytosolic Fructose Bisphosphate Aldolase genes in Arabidopsis [D]. Shandong agriculture university, Taian 
474 Wilhelm M, Schlegl J, Hahne H, Gholami AM, Lieberenz M, Savitski MM, Ziegler E, Butzmann 475 L, Gessulat S, Marx H, Mathieson T, Lemeer S, Schnatbaum K, Reimer U, Wenschuh H, 476 Mollenhauer M, Slotta-Huspenina J, Boese JH, Bantscheff M, Gerstmair A, Faerber F, Kuster $477 \quad \mathrm{~B}(2014)$ Mass-spectrometry-based draft of the human proteome.Nature 509: 582-587

478 Wiśniewski JR, Zougman A, Nagaraj N, Mann M (2009) Universal sample preparation method 479 for proteome analysis. Nature methods 6: 359-362

480 Wu X, Xiong E, Wang W,Scali M,Cresti M (2014) Universal sample preparation method 481 integrating trichloroacetic acid/acetone precipitation with phenol extraction for crop 482 proteomic analysis. Nature protocols 9:362-374

483 Zeng Y, Pan Z, Ding Y, Zhu A, Cao H, Xu Q, Deng X (2011) A proteomic analysis of the 484 chromoplasts isolated from sweet orange fruits (Citrus sinensis (L.) Osbeck), Journal of 485 experimental botany 62:5297-309

486 Zhang C, Huang J, Li X (2015) Identification of appropriate reference genes for RT-qPCR analysis 487 in Ziziphus jujuba Mill. Scientia Horticulturae 197: 166-169

489

Zhu W, Hu J, Wang X, Tian J, Komatsu S (2015) Organ-specific analysis of mahonia using gel490

491

492

493

494

495

496

497

498

499

500

501

502

503

504

505

506

507 free/label-free proteomic technique. Journal of Proteome Research 14:2669-2685

Figure legends

508 Fig. 1 Venn diagram of the number of expressed genes with RPKM $\geqslant 1$ and the identified proteins in the proteome of Jujube flowers. 
510 Fig. 2 Comparison of proteomics and RNA-Seq data generated from Jujube flowers. (A)

511 Distribution of RPKM values in different levels. (B) Distribution of RPKM values of 512 identified and unidentified genes in proteomic. (C) Distribution of protein abundance 513 (iBAQ intensities) (FDR =1\%). (D) A density scatter plot of iBAQ versus RPKM values. 514 The colour indicates the percentage points that were included in a region.

515 Fig. 3 Lists of ten highly ranked GO categories of proteome and their corresponding transcriptome.

516 (A) biological progress, (B) cellular components, (C) molecular function.

517 Fig. 4 Cumulative protein mass from the highest to the lowest abundance proteins identified in $518 \quad$ Jujube flowers.

519 Fig. 5 Phylogenetic analysis of the S locus-linked F-box genes from different taxa exhibiting SRNase-based GSI and seven F-box genes of Ziziphus jujuba located in the same chromosome as the S-RNase gene. The neighbour-joining tree was constructed based on aligned amino acid sequences corresponding to those S locus-linked F-box genes from well characterized S haplotypes in each plant species using Mega 6.0 (bootstrap=1,000). Zj. jz039541036 was the pollen-specificity candidate SFB gene of Jujube.

Fig. 6 (A) Transcriptomic and (B) RT-PCR analysis of candidate S-locus F-box genes expression in different organs: fruit 1: young fruit, fruit 2: red fruit, flower: opening flower. The number of each photo was corresponding to the F-box genes listed in Table S2. 


\section{Figure 1 (on next page)}

Venn diagram of the number of expressed genes with RPKM $\geq 1$ and the identified proteins in the proteome of Jujube flowers. 


\section{PeerJ \\ Total mRNAS}

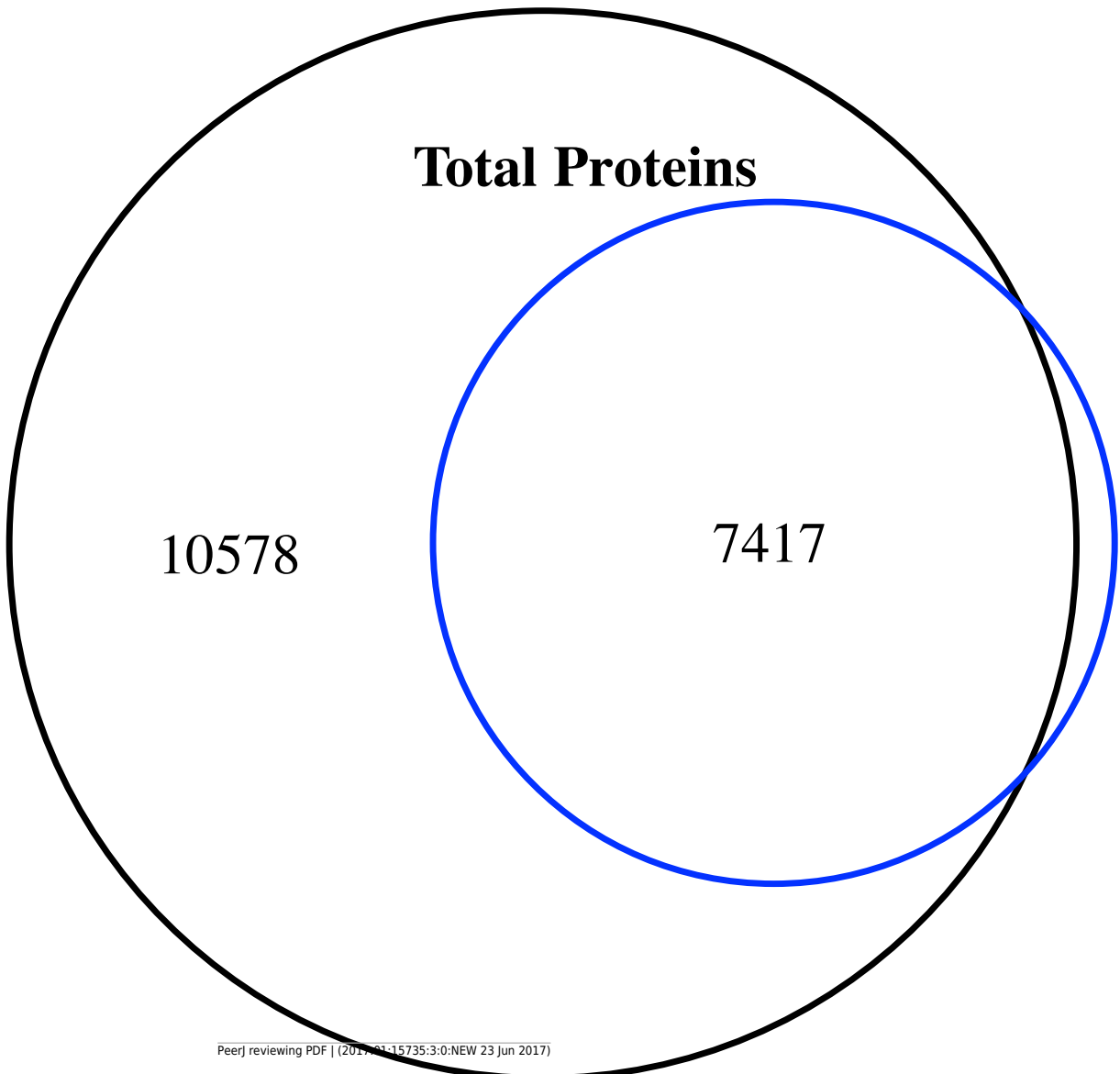


Figure 2

Comparison of proteomics and RNA-Seq data generated from Jujube flowers.

(A) Distribution of RPKM values in different levels. (B) Distribution of RPKM values of identified and unidentified genes in proteomic. (C) Distribution of proteins abundance (iBAQ intensities,FDR $=1 \%$ ). (D) A density scatter plot of iBAQ versus RPKM values. The colour indicates the percentage points that were included in a region representing a specific colour.

(A)

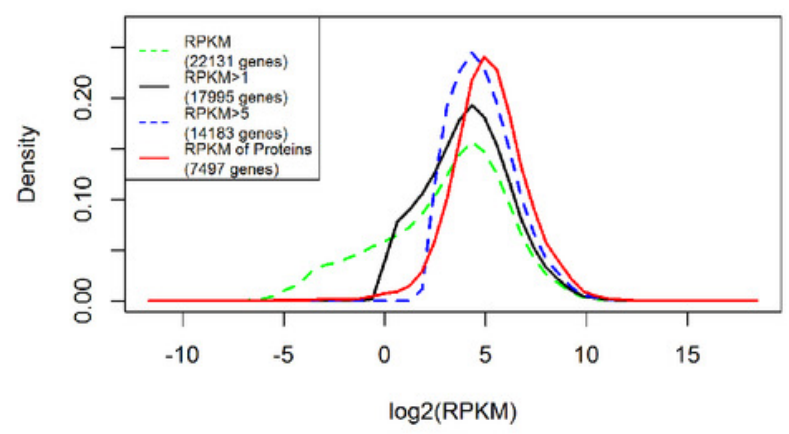

(C)

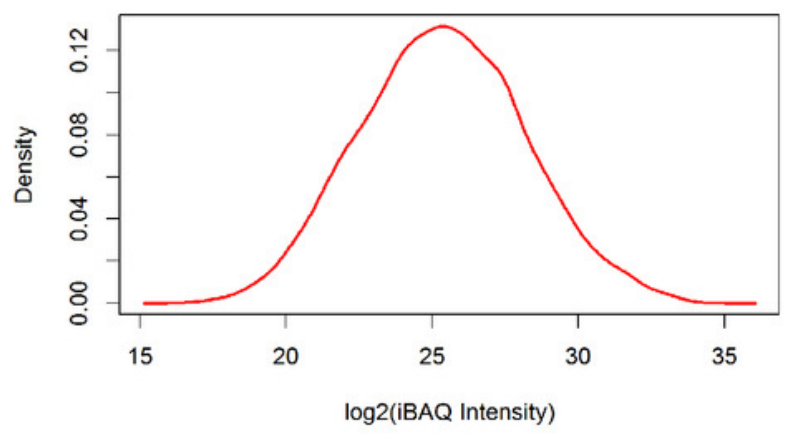

(B)

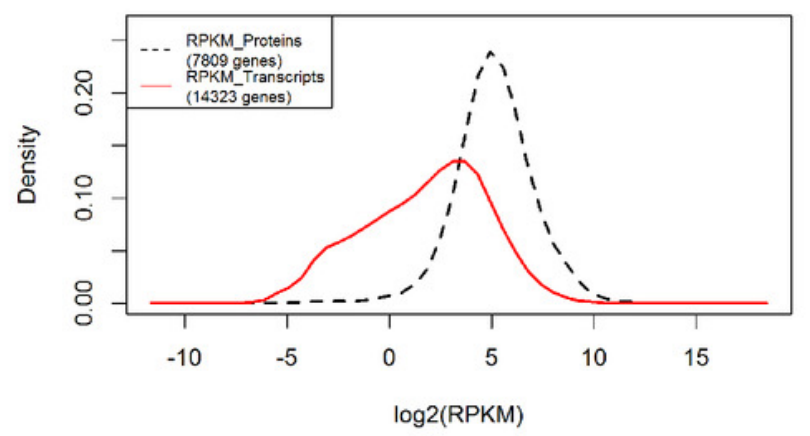

(D)

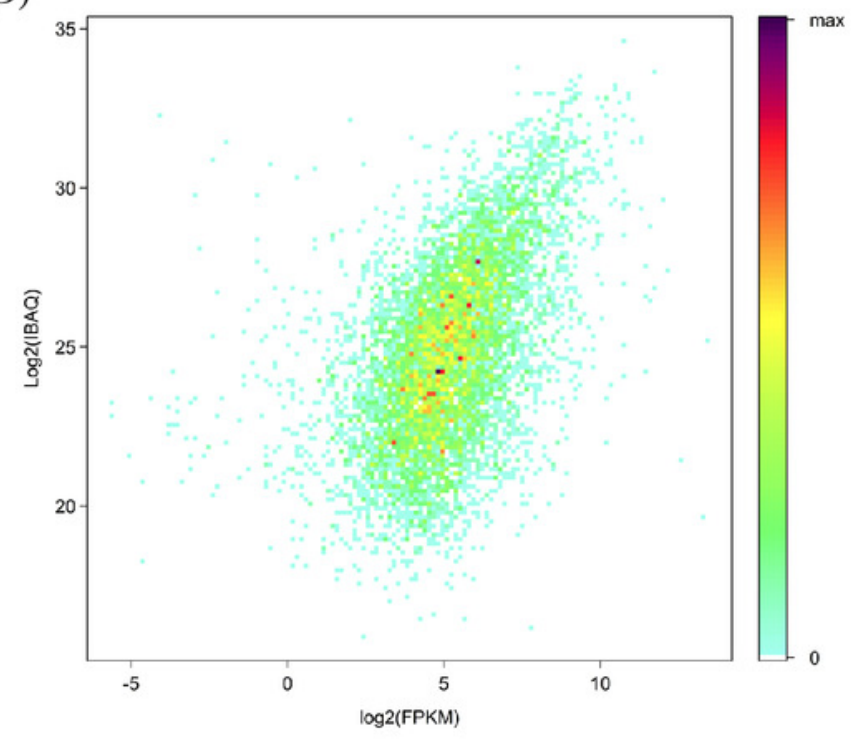




\section{Figure 3 (on next page)}

Lists of ten highly ranked GO categories of proteome and their corresponding transcriptome.

(A) biological progress, (B) cellular components, (C) molecular function. 
protein folding

transmembrane transport

intracellular protein transport

regulation of transcription, DNA-dependent

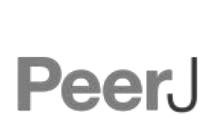

- Proteome

$\square$ Transcriptome

(A)

carbohydrate metabolic process

protein phosphorylation

metabolic process

oxidation-reduction process
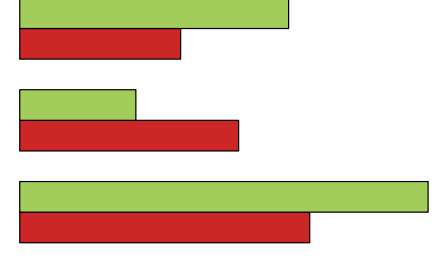

\section{Manuscript to be reviewed}
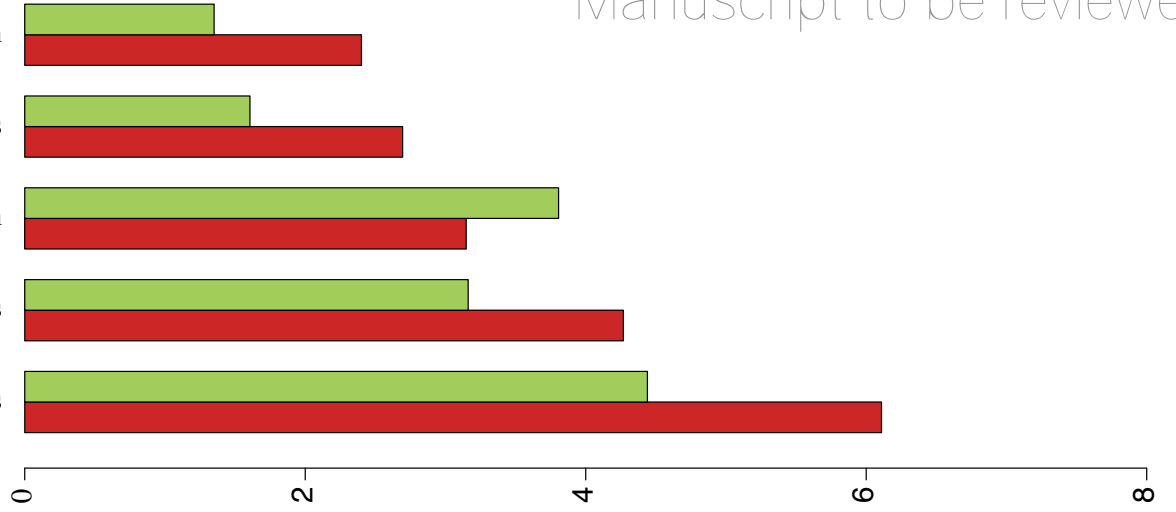

proteasome core complex

extracellular region

nucleosome

cell wall

cytoplasm

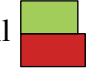

integral to membrane
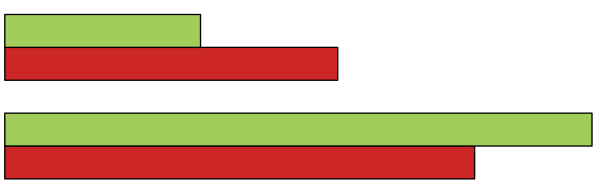

ribosome

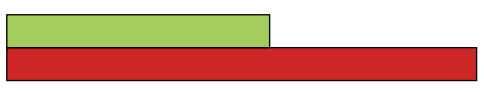

nucleu
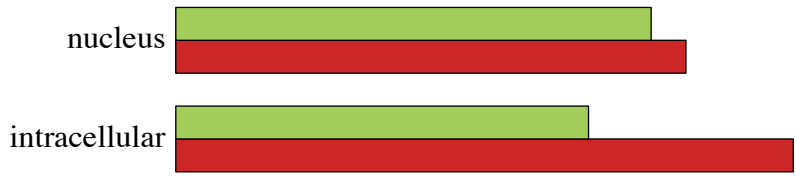

membrane

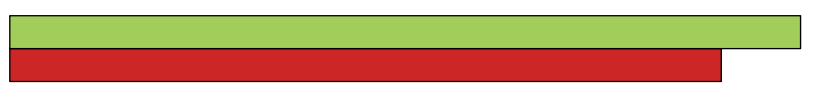

${ }^{\circ}$

○

-

N

$m$

$\forall$

structural constituent of ribosome

DNA binding

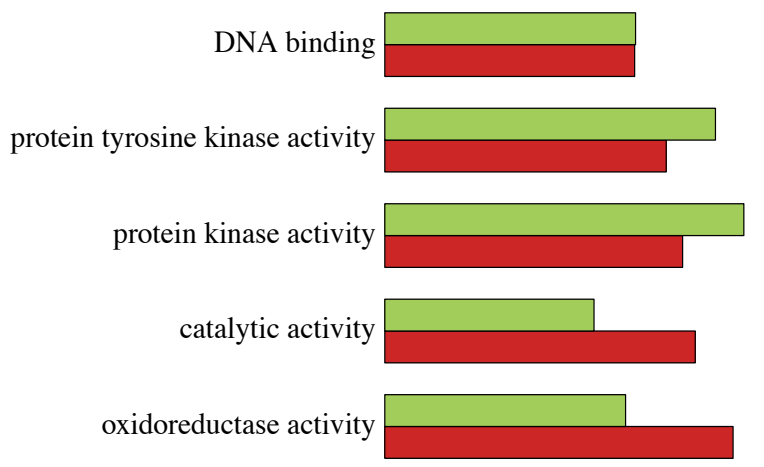

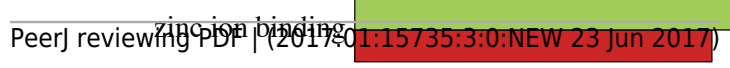

nucleic acid bindin

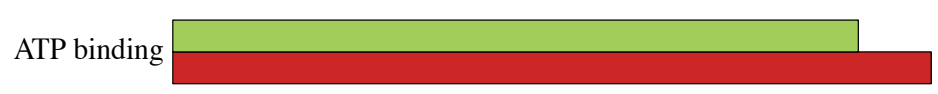

protein binding
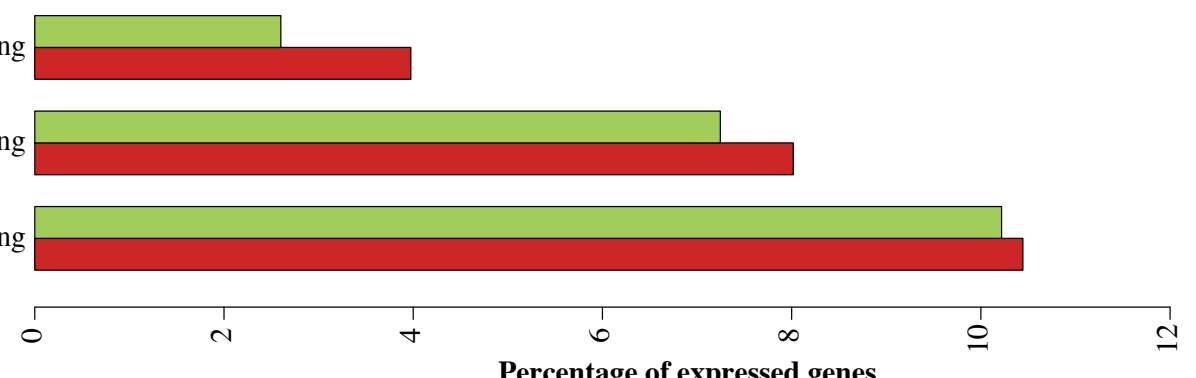

Percentage of expressed genes 
Figure 4

Cumulative protein mass from the highest to the lowest abundance proteins identified in jujube flowers.

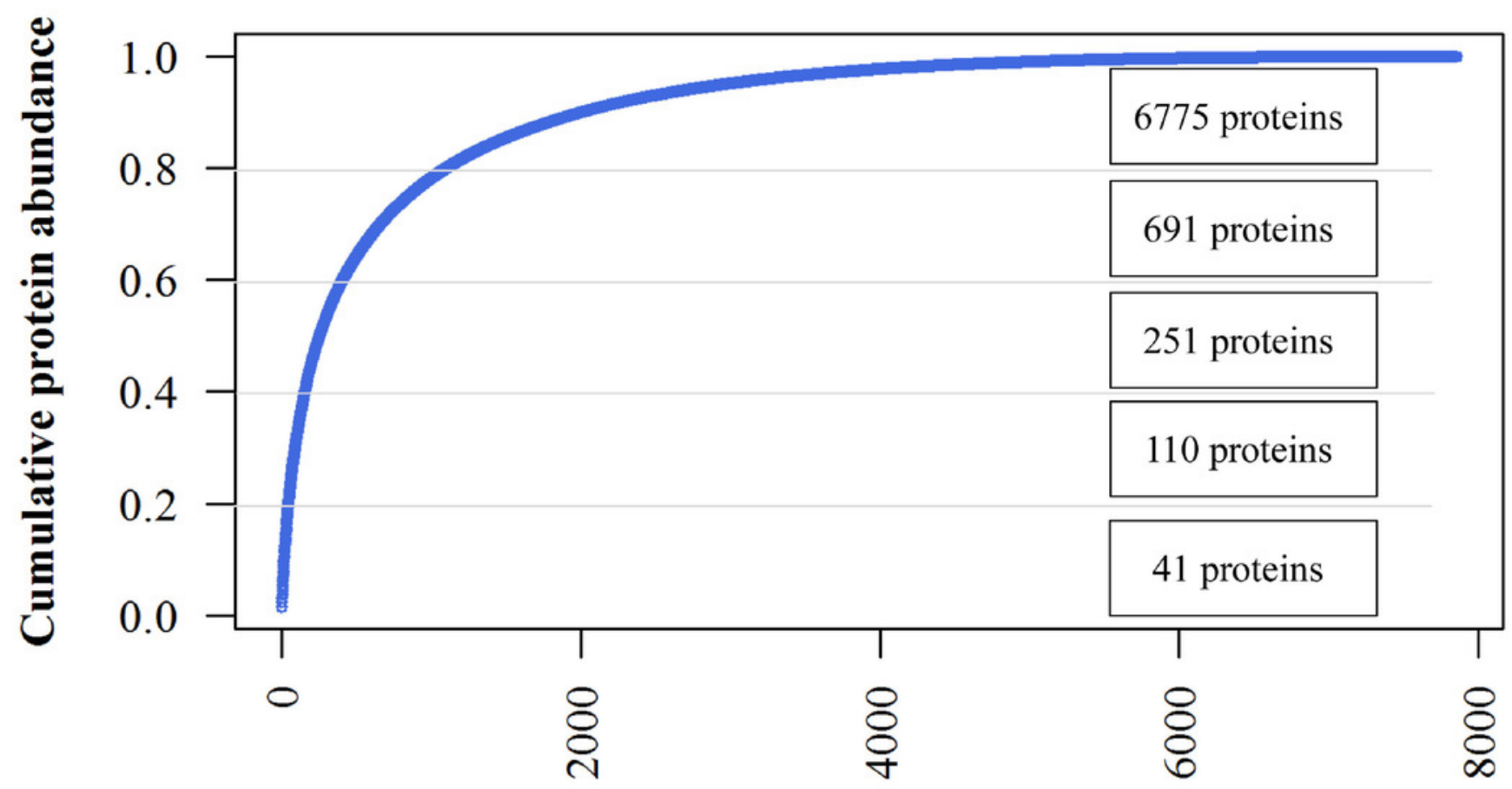

Ranked Proteins 
Figure $\mathbf{5}$ (on next page)

Phylogenetic analysis of the S locus-linked F-box genes from different taxa exhibiting SRNase-based GSI and seven F-box genes of Ziziphus jujuba located in the same chromosome with the S-RNase gene.

The neighbor-joining tree was constructed based on aligned amino acid sequences corresponding to those $\mathrm{S}$ locus-linked F-box genes from well characterized $\mathrm{S}$ haplotypes in each plant species using Mega 6.0 (bootstrap=1,000). Zj. jz039541036 was the pollenspecificity candidate SFB gene of Jujube. 


\section{Figure 6 (on next page)}
(A) Transcriptomic and (B) RT-PCR analysis of candidate S-locus F-box genes expression in different organs. fruit 1: young fruit, fruit 2: red fruit, flower: opening flower.

The number of each photo was corresponding to the F-box genes listed in Table S2. 
PeerJ
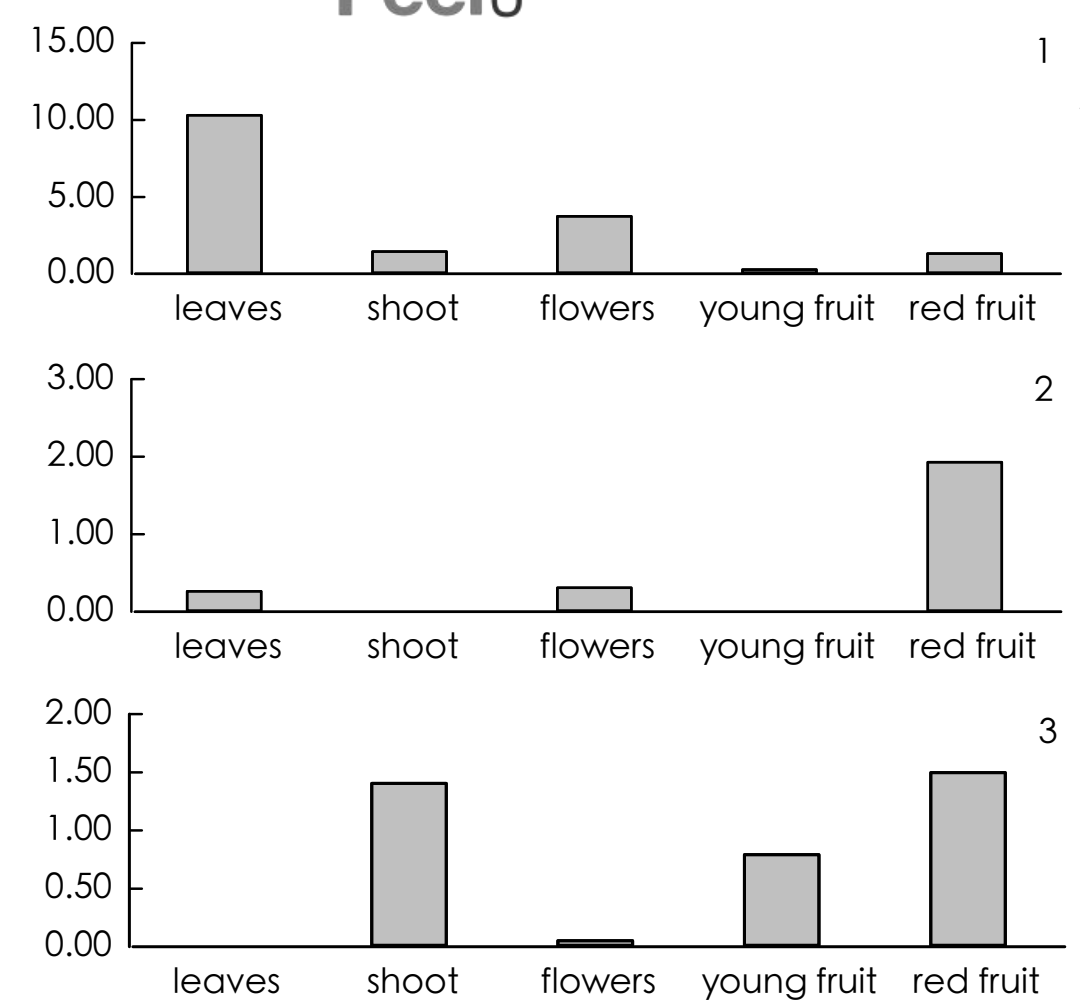

$\frac{2}{2}$
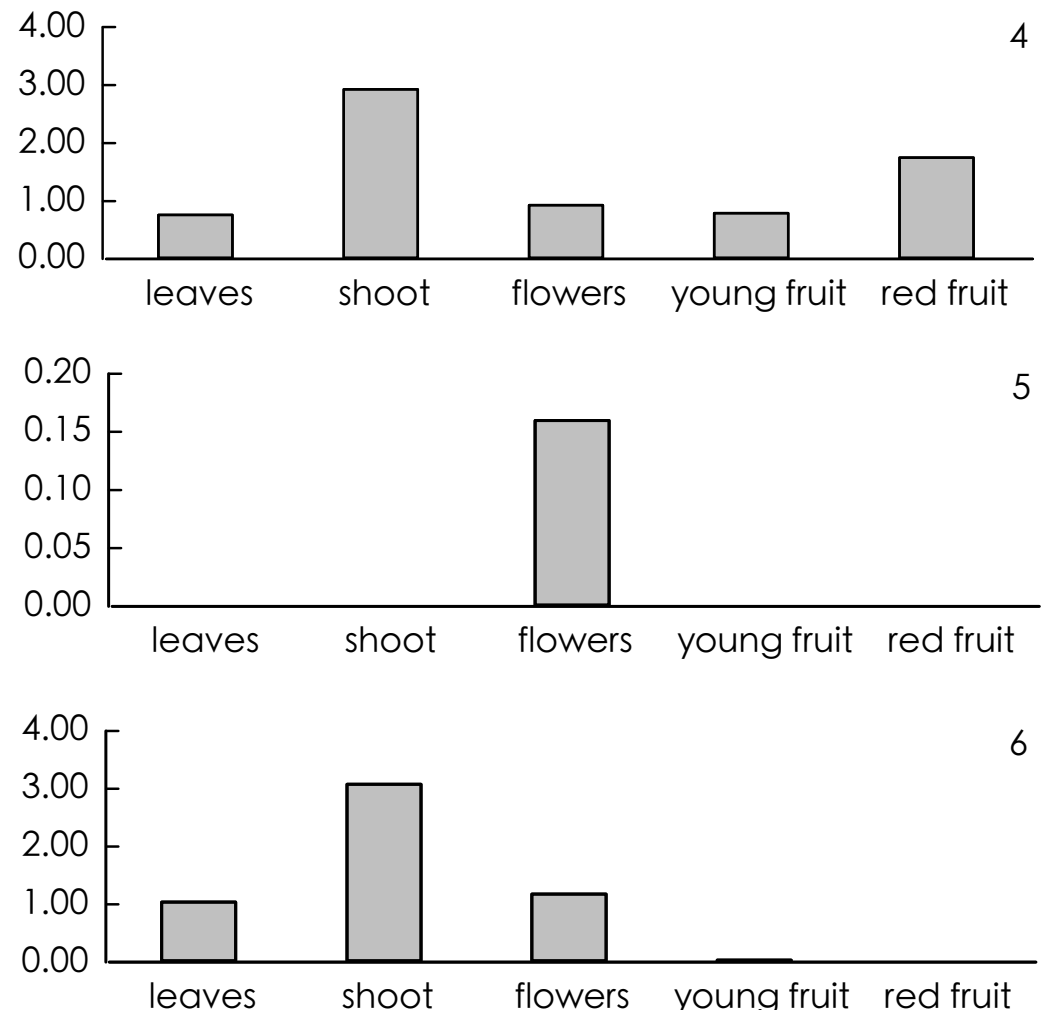

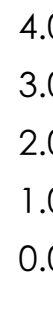

$\vdots$

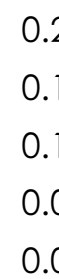

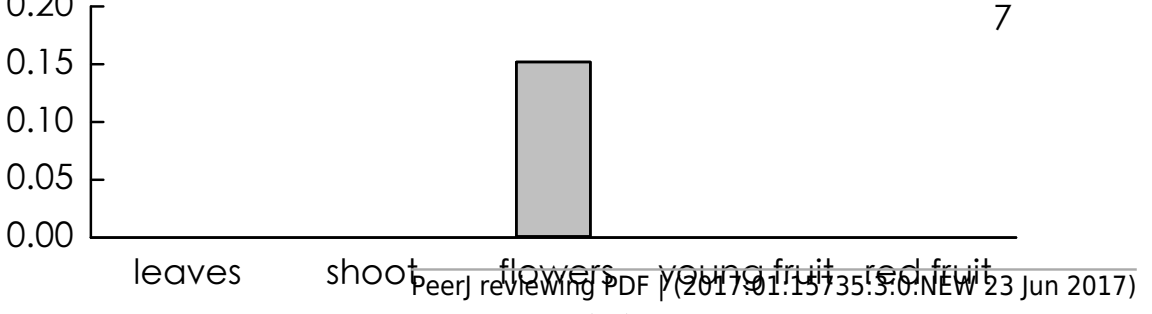

(A)

3
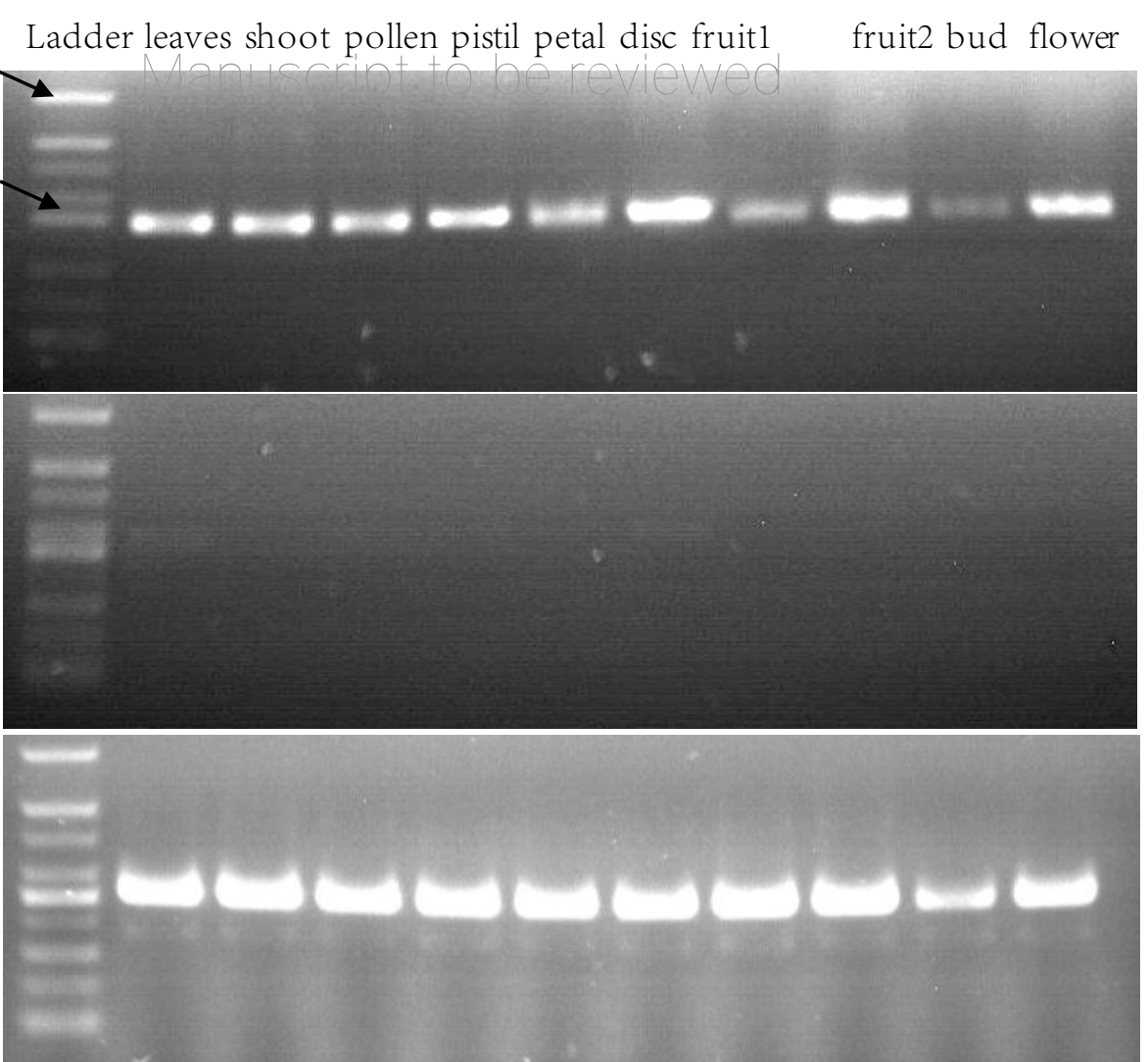

$\sin$

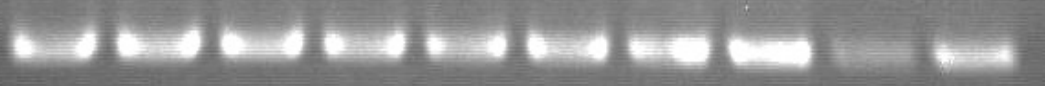

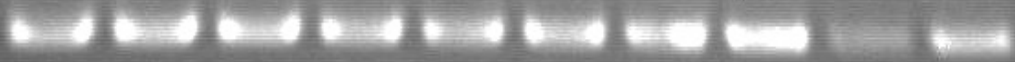

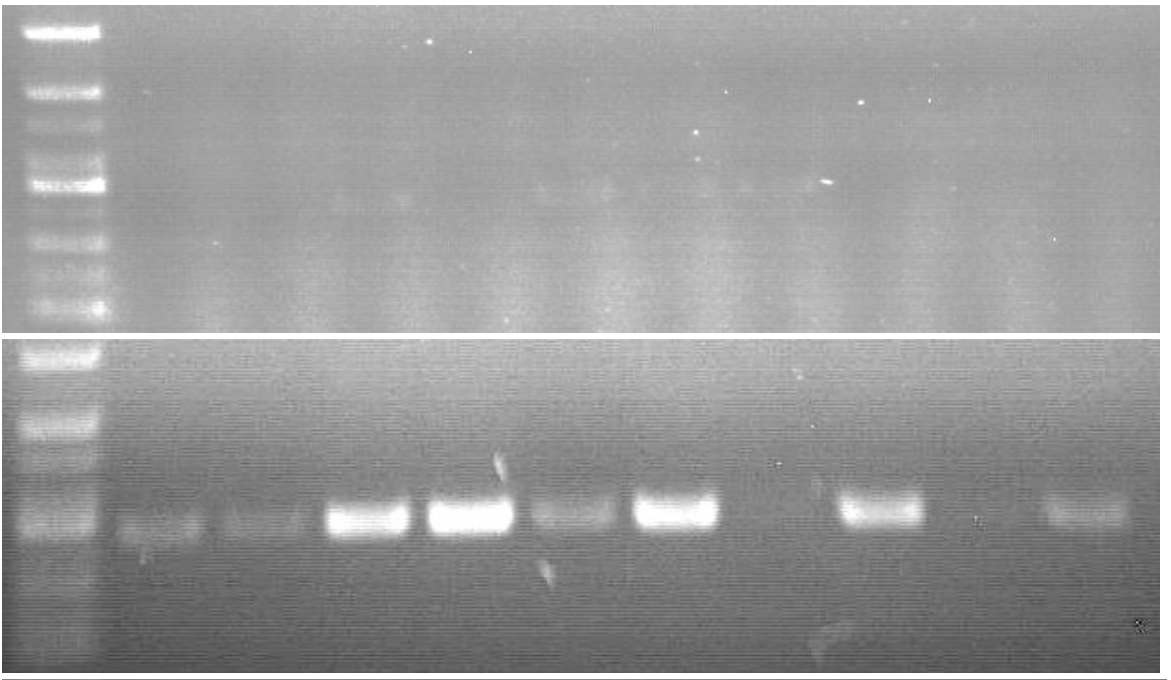

(B) 